\title{
Marginal and internal fit of interim crowns fabricated with 3D printing and milling method
}

\author{
Young-Tak Son ${ }^{1,2}$, KeunBaDa Son ${ }^{1,2}$, Kyu-Bok Lee , $^{1,2 * 3 *}$ \\ 'Department of Dental Science, Graduate School, Kyungpook National University, Daegu, Republic of Korea \\ ${ }^{2}$ Advanced Dental Device Development Institute, Kyungpook National University, Daegu, Republic of Korea \\ ${ }^{3}$ Department of Prosthodontics, School of Dentistry, Kyungpook National University, Daegu, Republic of Korea
}

Purpose: The purpose of this study was to assess the marginal and internal fit of interim crowns fabricated by two different manufacturing method (subtractive manufacturing technology and additive manufacturing technology). Materials and Methods: Forty study models were fabricated with plasters by making an impression of a master model of the maxillary right first molar for ceramic crown. On each study model, interim crowns $(n=40)$ were fabricated using three types of 3D printers (Meg-printer 2; Megagen, Zenith U; Dentis, and Zenith D; Dentis) and one type milling machine (imes-icore 450i; imes-icore GmbH). The internal of the interim crowns were filled with silicon and fitted to the study model. Internal scan data was obtained using an intraoral scanner. The fit of interim crowns were evaluated in the margin, absolute margin, axial, cusp, and occlusal area by using the superimposition of 3D scan data (Geomagic control X; 3D Systems). The Kruskal-wallis test, Mann-Whitney U test and Bonferroni correction method were used to compare the results among groups $(\alpha=0.05)$. Results: There was no significant difference in the absolute marginal discrepancy of the temporary crown manufactured by three 3D printers and one milling machine $(P=0.812)$. There was a significant difference between the milling machine and the 3D printer in the axial and occlusal area $(P<0.001)$. The temporary crown with the milling machine showed smaller axial gap and higher occlusal gap than 3D printer. Conclusion: Since the marginal fit of the temporary crown produced by three types of 3D printers were all with in clinically acceptable range $(<120 \mu \mathrm{m})$, it can be sufficiently used for the fabrication of the temporary crown. (J Dent Rehabil Appl Sci 2020;36(4):254-61)

Key words: 3D printer; milling; temporary crown; marginal fit; superimposition

\section{서론}

임시 보철물은 최종 보철물 제작 기간 동안 예기치 못 한 상황의 경우 치주 조직의 손상을 방지하며 지대치를 보호할 뿐만 아니라 구강 기능 및 심미성의 유지에 필수 적이다. ${ }^{1,2}$ 임시 보철물은 치아 형성부터 최종 합착 작업 까지 사용되는 고정성 보철 치료의 중요한 부분이다. ${ }^{3,4}$

환자 구강 내에서 레진을 이용하여 임시 보철물을 제 작하는 방법은 빠르고 간단하지만, 레진의 잔여 단량체

${ }^{*}$ Correspondence to: Kyu-Bok Lee

Professor, Department of Prosthodontics, School of Dentistry, Advanced Dental Device Development Institute, Kyungpook National University, 2177 Dalgubuldaero, Jung-gu, Daegu, 41940, Republic of Korea

Tel: +82-53-600-7674, Fax: +82-53-427-0778, E-mail: kblee@knu.ac.kr

Received: October 5, 2020/Last Revision: October 29, 2020/Accepted: October 30,2020
가 구강 점막에 해를 끼쳐 알레르기성 구내염을 유발할 수 있다. ${ }^{5}$ 반대로 임시 보철물은 모형을 통해 제작될 수 있지만, 작업자의 기술 및 제작 과정에서 오류가 발생할 수 있다. ${ }^{6}$ 작업자 사이의 기술력 편차로 인해서 결과물 의 차이가 발생할 수 있으며, 실패 시 처음부터 다시 제 작해야 하며 작업시간이 길다는 단점들이 있다. 반면 최 근 computer aided design and computer aided manufacturing $(\mathrm{CAD} / \mathrm{CAM})$ 시스템은 치과용 보철물 생산에 이용 가능해져 이전의 제작 과정에서 발생하는 단점들을

Copyright@ 2020 The Korean Academy of Stomatognathic Function and Occlusion. (c) It is identical to Creative Commons Non-Commercial License. 
감소할 수 있다. ${ }^{7}$

치과 $\mathrm{CAD} / \mathrm{CAM}$ 방식은 절삭 가공(subtractive manufacturing)과 적층 가공(additive manufacturing)으로 구 분된다. 치과 분야에서의 $\mathrm{CAD} / \mathrm{CAM}$ 시스템은 밀링 버 를 사용해 블록을 삭제하여 원하는 형상을 얻어내는 방 식인 절삭 가공을 활발히 사용하고 있다. ${ }^{8}$ 하지만 밀링 버의 동작 범위 제약으로 인해 복잡한 형상을 재현하기 어렵고 밀링 버의 직경에 따라 언더컷 재현 능력에 차이 를 보이며 보철물 제작 시 재료의 낭비가 심한 단점이 있 다. ${ }^{9}$ 또한 절삭하고 남은 블록 부산물은 재사용이 불가능 해 재료의 낭비가 심하고 가공을 위한 밀링 버의 소모가 많아 유지 비용이 발생하게 된다. ${ }^{10,11}$ 적층 가공 방식인 $3 \mathrm{D}$ 프린터는 $3 \mathrm{D}$ 모델 데이터를 다중 슬라이스 이미지 로 변환하고 재료를 연속적으로 쌓아 올려 결과물을 얻 는다. ${ }^{12,13}$ 레이저를 조사하여 필요한 부위에만 여러 개의 층을 쌓아 결과물을 제작하기 때문에 복잡한 형상을 재 현할 수 있고 재료의 낭비가 적으며 또한 소음이 적고 정 밀도가 비교적 높은 장점이 있다. ${ }^{14}$ 하지만 소재의 비용이 높고 레진의 청소가 어렵다는 단점이 있다.

대표적인 3D 프린팅 기술은 stereolithography apparatus (SLA), digital light processing (DLP) 그리고 fused deposition modeling (FDM) 타입으로 구분된다. 그 중 에서 $\mathrm{FDM}$ 기술은 장비와 재료비가 저렴해 가장 대중화 된 방식이지만 SLA와 DLP 기술에 비해 정밀도가 낮고 출력물의 표면이 거칠다는 단점이 있어 비교적 정밀도가 높은 SLA와 DLP 기술이 치과용 $3 \mathrm{D}$ 프린터로 주로 사 용되고 있다. ${ }^{15-17} \mathrm{SLA}$ 와 DLP 기술은 빛으로 원료를 굳 혀 입체 모형을 만드는 광경화 적층 방식이다. SLA 기술 의 $3 \mathrm{D}$ 프린터는 광경화성 액상 레진에 점 형태의 레이저 를 사용하여 특정 단일 지점을 경화시키고 반사경을 이 용하여 레이저를 원하는 부위로 이동시키며 경화가 되는 방식이다. DLP 타입의 3D 프린터는 광경화성 액상 레진 을 경화시키는 광원으로 점 형태의 레이저 대신 프로젝터 를 이용해, 한 층 전체를 한 번에 조사하여 경화시켜 적층 하는 방식이다.

적층 가공과 절삭 가공을 이용한 보철물의 제작은 디 지털 시대에 따라 계속적으로 발전하고 있으며, 지속적인 평가를 통해 발전되어가고 있는 가공 기술과 사용하는 재료들의 안정성과 완성도를 높일 수 있다. ${ }^{18,19}$ 적층 가 공 및 절삭 가공을 통해 제작된 보철물을 평가하는 방법 으로 기계적 특성, 색상, 및 출력물 정확도와 같은 방법들 이 있다. ${ }^{20}$ 그 중에서도 치주염, 치아 우식, 보철물의 파절
및 탈락에 임상적으로 영향을 미칠 수 있는 보철물 변연 및 내면 적합도 평가는 중요하다. ${ }^{21,22}$ 치과 보철물 적합도 에 관한 실험적 평가 방법은 절단면 측정법, 실리콘 복제 방법, $3 \mathrm{D}$ 스캔 데이터 중첩법, 무게 측정법, 마이크로 CT 측정법 등이 있다. ${ }^{23,24}$ 그 중에서 $3 \mathrm{D}$ 스캔 데이터 중첩법 은 스캐닝 과정에서 얻은 스캔 데이터를 통해 절단면 측 정법 및 실리콘 복제 방법과 다르게 비 파괴적이고 분실 의 우려가 없으며 원하는 부위의 변연 및 내면 적합도를 분석할 수 있어 현재 치과 분야의 연구 영역에서 적용되 고 있다. ${ }^{25,26}$

현재 치과에서는 $3 \mathrm{D}$ 프린터를 이용하여 수술 유도 장 치, 모형, 임시 보철물 등을 제작하는 것이 증가하고 있으 며 다양한 $3 \mathrm{D}$ 프린터가 개발되고 있다. 따라서 적층 가 공 기술로 제작된 보철물에 대한 연구가 더 필요하다. 따 라서 본 연구의 목적은 서로 다른 제작 방법인 절삭 가공 과 적층 가공 기술로 제작된 임시 보철물의 변연 및 내면 적합도를 3차원 데이터 중첩 방법으로 평가하고자 한다. 연구의 귀무가설은 절삭 가공과 적층 가공으로 제작된 임시 보철물의 변연 및 내면 적합도는 차이가 없다는 것 이다.

\section{연구 재료 및 방법}

본 연구는 Fig.1과 같은 과정으로 진행되었다.

기준 모형으로 구강 모형(ANA-4; Frasaco GmbH, Tettnang, Germany)의 상악 우측 제1대구치를 사용했 다. 상악 우측 제 1 대구치의 형성 조건은 교합면 방향으로 $1.5 \mathrm{~mm}$ 삭제, 축벽 $1 \mathrm{~mm}$ 삭제, 변연은 치은 연상의 위치 에서 $1.2 \mathrm{~mm}$ 샘퍼 형태가 되도록 삭제하였고 $6^{\circ}$ 의 수렴 각이 되도록 형성하였다. 기준 모형을 Soft Putty (Aquasil Soft Putty; Dentsply, Pannsylvania, USA)를 이용하 여 인상을 채득하였다. 작업 모형을 제작하기 위해 제조 사의 지침에 따라 치과용 경석고(Snow rock; Mungyo, Gimhae, South Korea)를 교반하여 인상에 주입하고 1시 간 동안 경화 후 인상을 제거하여 총 40 개의 작업 모형을 제작하였다.

각각의 작업 모형을 구강 스캐너(i500; Medit, Seoul, South Korea)로 스캔하여 40 개의 스캔 데이터를 획득하 였다(Fig. 2A). 스캔이 완료된 데이터를 캐드 디자인 프로 그램(3Shape dental system; 3Shape, Copenhagen, Denmark)을 사용하여 임시 보철물을 디자인하였다. 디자인 시 변연 설정 후 시멘트 공간 설정 값은 변연 상방 $1 \mathrm{~mm}$, 


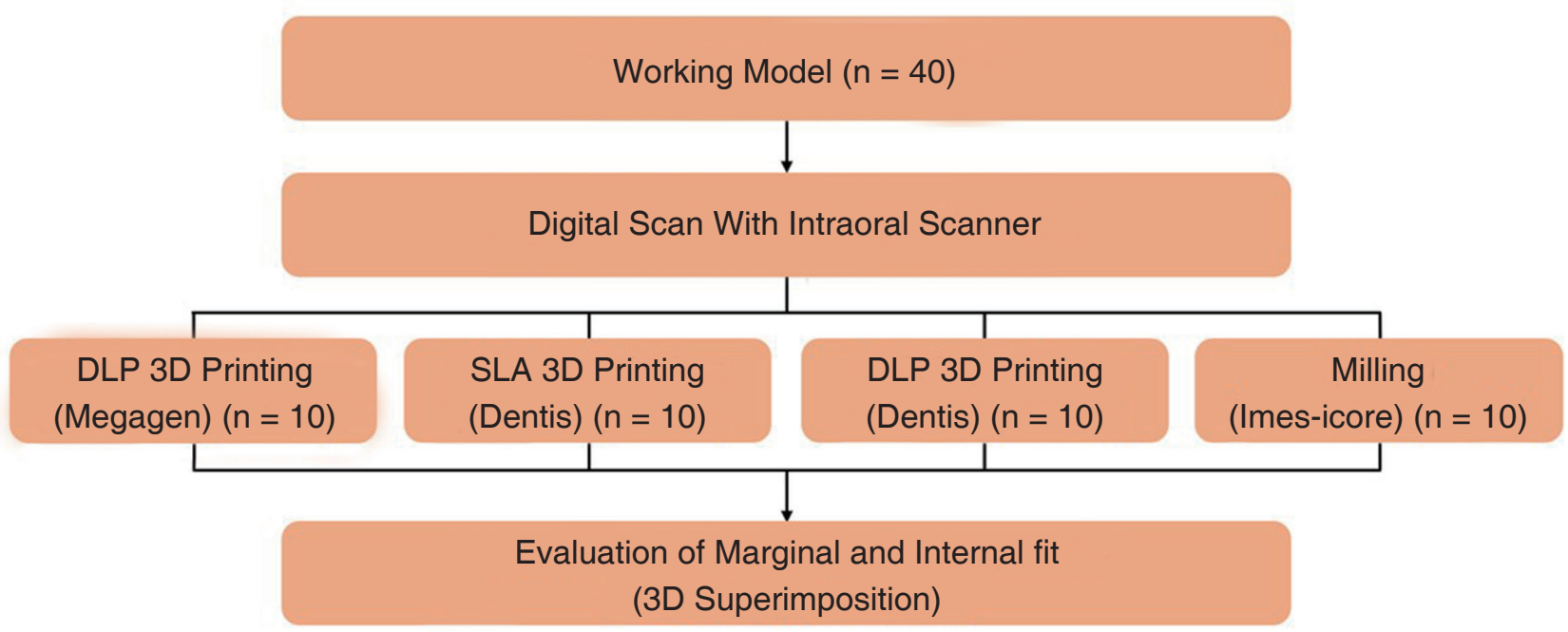

Fig. 1. Experimental design.
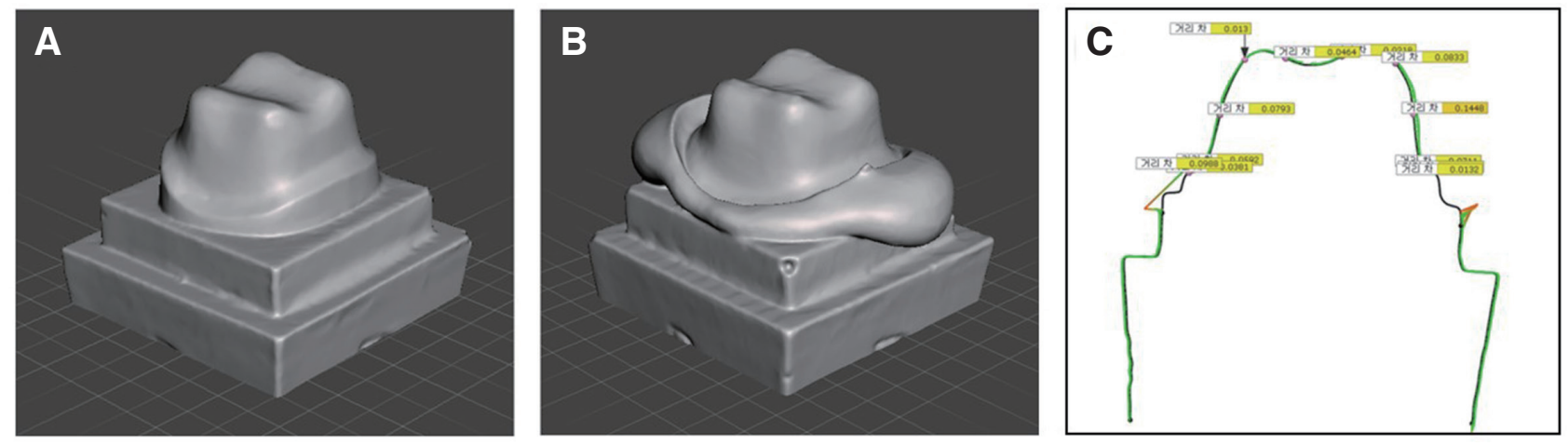

Fig. 2. (A) Scan data of definitive model, (B) Scan data of definitive model with silicone paste, (C) Cross-sectional image of the superimposition of $(A)$ and $(B)$ for marginal and internal fit assessment.

내면 시멘트 공간은 $80 \mu \mathrm{m}$, 변연 인접 영역 시멘트 공간 은 $60 \mu \mathrm{m}$ 로 설정하였다. 디자인이 완료된 파일은 3종의 3D 프린터(Meg-printer group [Meg-printer 2; Megagen, Daegu, South Korea], Zenith U group [Zenith U; Dentis], 그리고 Zenith D group [Zenith D; Dentis, Daegu, South Korea]), 1종의 밀링 장비(Milling group [imesicore 450i; imes-icore GmbH, Eiterfeld, Germany])를 사용하여 각 장비당 10 개, 총 40 개의 임시 보철물을 제작 하였다. 이때, 3 가지의 $3 \mathrm{D}$ 프린터 모두 적층 두께 조건을 $100 \mu \mathrm{m}$ 로 설정하였다. Meg-printer는 전용의 레진 용액 (RAYDENT C\&B; Ray, Seoul, South Korea), Zentih U 와 Zenith D는 전용의 레진 용액(ZMD-1000B; Dentis) 을 사용하였고, 밀링은 폴리메탈메타아크릴레이트 블록 (PMMA DISK; Ymahachi dental mpg, Aichi Pref, Ja- pan)을 사용하였다. 후 처리는 각 제조사의 지침에 따라 진행되었다.

제작된 임시 보철물 내면에 흐름성이 우수한 lightbody silicone (Aquasil Ultra XLV; Dentsply, Pannsylvania, USA)을 채워 넣고 작업 모형과 짝을 맞추어 적합 시 켰다. 실리콘이 완전히 중합될 때까지 손가락으로 가압 하였으며, 중합이 완료된 후 지대치에서 실리콘이 분리 되지 않도록 임시 보철물을 조심스럽게 제거하였다. 실 리콘의 얇은 막으로 내면이 복제되어 있는 작업 모형을 구강 스캐너를 사용하여 스캔 데이터를 획득하였다(Fig. 2B). 작업 모형 스캔 데이터와 내면이 복제되어 있는 스 캔 데이터를 3차원 검사 소프트웨어(Geomagic control X, release 2018.0.0; 3D Systems, Cary, USA)를 사용하 여 중첩 및 평가하였다. 두 스캔 데이터를 소프트웨어 


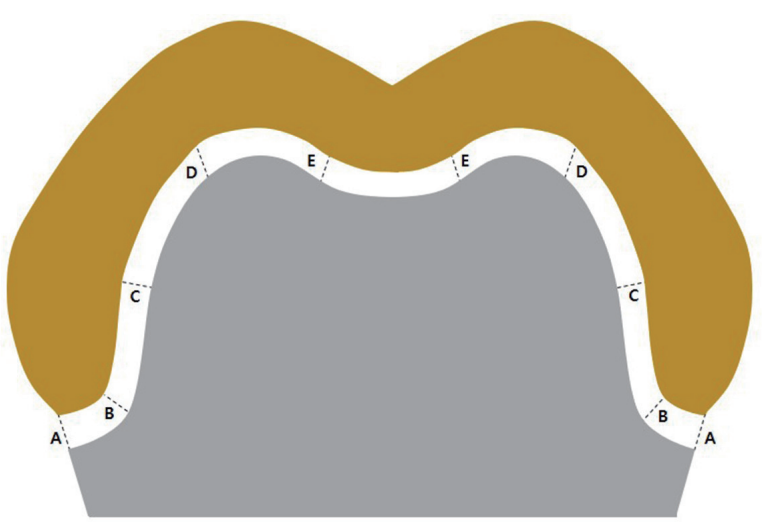

Fig. 3. Schematic of measurement points for marginal and internal fit. (A) Marginal region, (B) Chamfer region, (C) Axial region, (D) Cusp region, (E) Occlusal region.

에 불러오고 초기 정렬(initial alignment)을 하였다. 정확 한 중첩을 위해 불필요한 부분을 제거하고, 최적화 정렬 (best-fit alignment)을 하였다. 두 스캔 데이터가 정확한 위치로 정렬되었는지 확인하였다. 실리콘 두께의 측정을 위해서 작업 모델의 협설 및 근원심 방향으로 작업 모델 중심을 지나는 두 개의 가상 평면을 설정하였다. 그리고 형성된 두 개의 가상 평면은 모든 시편에서 동일한 좌표 에서 설정되어 졌고, 동일한 위치에서 근원심 및 협설 방 향의 절단면을 얻을 수 있게 하였다(Fig. 2C). 절단된 면 에서 절대 변연, 변연, 샘퍼, 축벽, 교두, 교합 영역의 간격 을 측정하였다(Fig. 3). 따라서 한 면에서 12 개의 간격이
측정되었고, 모든 면에서 총 480 개의 간격이 측정되었다.

모든 데이터는 SPSS statistical software (release 23.0; $\mathrm{IBM}, \mathrm{Chicago}, \mathrm{USA}$ )를 사용하여 분석되었다. 측정된 데이터는 정규분포를 이루지 않아 비 모수적인 통계 방 법을 사용하였다. 제작 방법의 차이를 비교하기 위해 Kruskal-Wallis test를 사용하여 검증하였으며, 사후 검정 을 위해 Mann-Whitney U-test and Bonferroni correction method를 사용하였다 $(\alpha=0.05)$.

\section{결과}

제작 방법 간 변연 및 내면 적합도를 비교한 값은 Table 1과 Fig. 4에 나타나 있다. 3종의 3D 프린터와 1종 의 밀링 장비에서 제작된 임시 보철물의 절대 변연 간격 은 통계적으로 유의한 차이가 없었다 $(P=0.812)$. 변연 간격은 Zenith D 그룹에서 가장 낮은 값 $(28.3 \pm 7.5 \mu \mathrm{m})$ 을 보였으나 $(P=0.012)$, 밀링 및 Zenith $\mathrm{U}$ 그룹과 유의 한 차이가 없었다 $(P>0.05)$.

축벽, 교합 간격에서 밀링 장비와 $3 \mathrm{D}$ 프린터 사이에 유 의한 차이가 있었다 $(P<0.001)$. 축벽 간격 결과는 밀링 장비(42.3 $\pm 9.4 \mu \mathrm{m})$ 가 3D 프린터(Zenith U; $75.6 \pm 20.8$ $\mu \mathrm{m}$, Zenith D; $92.3 \pm 25.4 \mu \mathrm{m}$, 및 Meg-printer; $96.5 \pm$ $14.3 \mu \mathrm{m})$ 보다 유의미하게 낮은 축벽 간격을 보였다(P $<0.001)$. 교합 간격에서는 밀링 장비 $(119 \pm 23.8 \mu \mathrm{m})$ 가 3종의 3D 프린터(Zenith U; $68.5 \pm 18.7 \mu \mathrm{m}$, Zenith D; $46.2 \pm$ 17.7, 그리고 Meg-printer; $54.9 \pm 19.4 \mu \mathrm{m})$ 보

Table 1. Comparison of marginal and internal fit of interim crowns fabricated with different 3D printers and milling machine

\begin{tabular}{|c|c|c|c|c|c|c|}
\hline \multirow{3}{*}{ Group } & \multicolumn{3}{|c|}{ Marginal Discrepancy } & \multicolumn{3}{|c|}{ Internal Discrepancy } \\
\hline & AMD & MG & Chamfer & Axial & Angle & Occlusal \\
\hline & \multicolumn{6}{|c|}{ Mean (SD) $\mu \mathrm{m}$} \\
\hline Milling group & $\begin{array}{l}104.4 \\
(38.5)\end{array}$ & $\begin{array}{c}45.5^{\mathrm{ab}} \\
(15.8)\end{array}$ & $\begin{array}{l}54.9^{\mathrm{ab}} \\
(12.8)\end{array}$ & $\begin{array}{c}42.3^{\mathrm{a}} \\
(9.4)\end{array}$ & $\begin{array}{l}74.4^{a} \\
(16.6)\end{array}$ & $\begin{array}{l}119^{a} \\
(23.8)\end{array}$ \\
\hline Zenith U group & $\begin{array}{c}99.9 \\
(36.8)\end{array}$ & $\begin{array}{l}42.1^{\mathrm{ab}} \\
(17.2)\end{array}$ & $\begin{array}{l}47.9^{\mathrm{a}} \\
(13.9)\end{array}$ & $\begin{array}{l}75.6^{b} \\
(20.8)\end{array}$ & $\begin{array}{c}72^{a} \\
(28.8)\end{array}$ & $\begin{array}{l}68.5^{b} \\
(18.7)\end{array}$ \\
\hline Zenith D group & $\begin{array}{l}100.5 \\
(34.2)\end{array}$ & $\begin{array}{c}28.3^{a} \\
(7.5)\end{array}$ & $\begin{array}{l}45.9^{a} \\
(15.8)\end{array}$ & $\begin{array}{l}92.3^{b} \\
(25.4)\end{array}$ & $\begin{array}{l}46.9^{b} \\
(18.3)\end{array}$ & $\begin{array}{l}46.2^{b} \\
(17.7)\end{array}$ \\
\hline Megagen group & $\begin{array}{c}111.3 \\
(34)\end{array}$ & $\begin{array}{l}53.7^{b} \\
(24.2)\end{array}$ & $\begin{array}{l}72.1^{b} \\
(19.5)\end{array}$ & $\begin{array}{l}96.5^{b} \\
(14.3)\end{array}$ & $\begin{array}{c}76^{\mathrm{a}} \\
(15.7)\end{array}$ & $\begin{array}{l}54.9^{b} \\
(19.4)\end{array}$ \\
\hline$P$ & $0.812^{*}$ & $0.012 *$ & $0.01 *$ & $<0.001^{*}$ & $0.01 *$ & $<0.001 *$ \\
\hline
\end{tabular}

*, Determined significance by Kruskal-Wallis test; $P<0.05$. Different letters indicate significant differences among fabrication methods by MannWhitney U-test and Bonferroni correction method. 


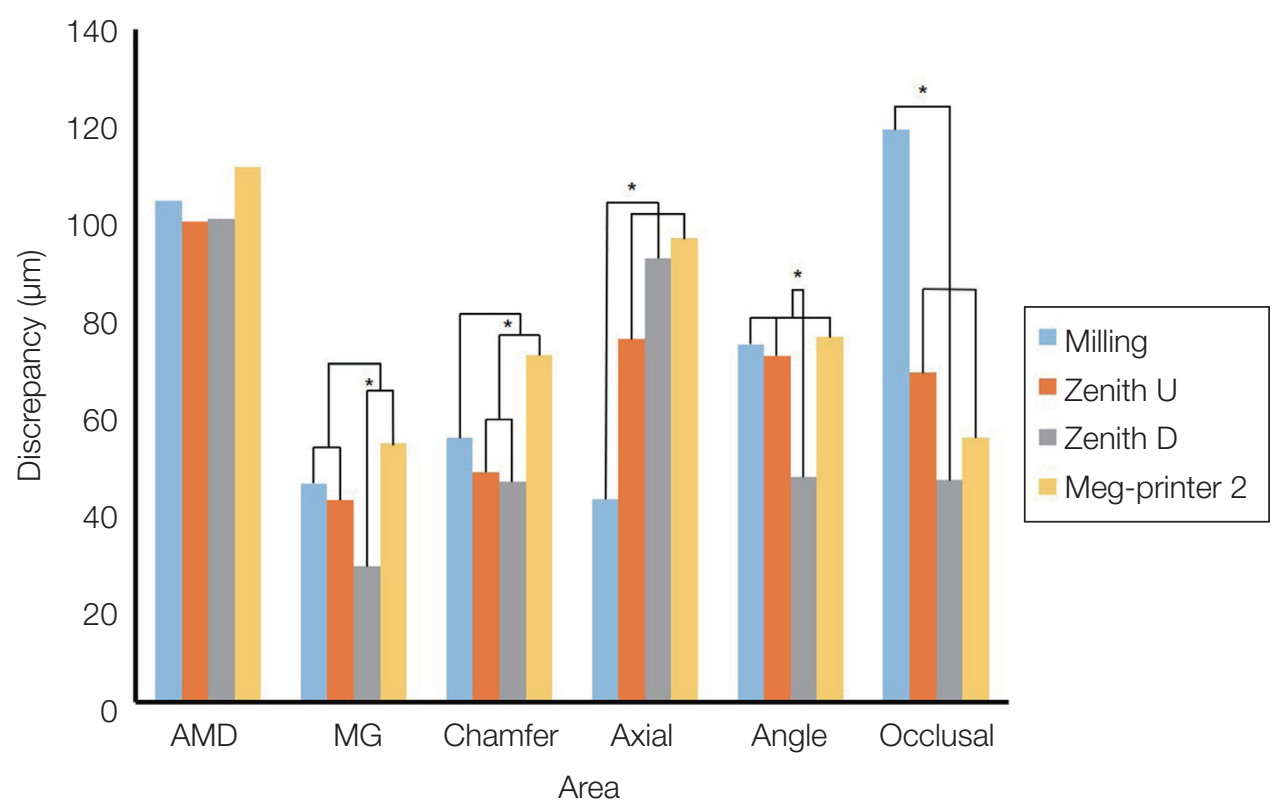

Fig. 4. Comparison of marginal and internal fit of interim crowns fabricated by 3D printing and milling technology. *Significant difference, $P<0.05$.

다 유의미하게 높은 교합 간격을 보였다 $(P<0.001)$. 샘 퍼 간격에서는 Zenith D 그룹에서 가장 낮은 값(45.9 \pm $15.8 \mu \mathrm{m})$ 을 보였으나 $(P=0.01)$ 밀링 및 Zenith $\mathrm{U}$ 그룹 과 유의한 차이가 없었다 $(P>0.05)$. 교두 간격에서는 Zenith D 그룹에서 가장 낮은 값 $(46.9 \pm 18.3 \mu \mathrm{m})$ 을 보 였으며 $(P=0.01)$ Zenit $\mathrm{U}$, Megagen 및 밀링 그룹과 유의 한 차이가 있었다 $(P<0.05)$.

\section{고찰}

본 연구의 목적은 서로 다른 제작 방법인 절삭 가공과 적층 가공 기술로 제작된 임시 보철물의 변연 및 내면 적 합도를 3차원 데이터로 중첩하여 평가하는 것이다. 본 연 구결과로 절대 변연 간격과 샘퍼를 제외한 모든 부위에 는 절삭 가공과 적층 가공 사이에 유의한 차이가 있었으 므로 부분적으로 귀무가설은 기각되었다 $(P<0.05)$.

임시 보철물의 치주염, 치아 우식, 보철물의 파절 및 탈 락에 영향을 미치는 임상적으로 연관된 보철물 적합도에 관한 평가는 중요한 요소 중 하나이다. ${ }^{21,22}$ 임상적으로 허 용된 변연의 간격은 많은 연구자들에 의해 제시되었다. 적합도를 평가하기 위해 통상적으로 제시되는 변연 간격 의 임상적 허용 범위는 $120 \mu \mathrm{m}$ 미만이다. ${ }^{4}$ 본 연구에서 3 종의 $3 \mathrm{D}$ 프린터 및 밀링 장비로 제작된 임시 보철물의 변
연 적합도는 모두 $120 \mu \mathrm{m}$ 이내의 간격을 보였기 때문에 임상적으로 허용 가능한 변연 적합도를 보였다.

Revilla-Léon 등 $^{27}$ 은 변연 간격에서는 유의한 차이를 보이지 않았지만 3D 프린터 $(91.86 \pm 2.88 \mu \mathrm{m})$ 가 밀링 장 비 $(96 \pm 1.97 \mu \mathrm{m})$ 보다 내면 간격에서 유의하게 낮은 변 연 간격을 보였다. 본 연구에서도 절대 변연 간격에서는 유의한 차이를 보이지 않았지만 $(P=0.812)$, 내면 간격 에서 유의한 차이를 보였다. 밀링 장비로 제작된 임시 보 철물은 $3 \mathrm{D}$ 프린터보다 작은 축벽 간격 $(42.3 \pm 9.4 \mu \mathrm{m})$ 과 높은 교합 간격 $(119 \pm 23.8 \mu \mathrm{m})$ 을 보였다. Grajower 등 $^{19}$ 이 얇은 시멘트 공간이 제공됐을 때 보철물이 완전히 안착하지 않는다는 것을 발견했다. 따라서 밀링 장비의 축벽 영역에서의 작은 축벽 간격은 해당 그룹 안에서 높 은 교합 간격과 밀접하게 관련될 수 있다. 또한 3D 프린 터 그룹의 임시 보철물의 교합 영역에서의 좋은 정확성은 제작 과정에서 기인한 것일 수 있다. 절삭 가공에서 보철 물은 밀링 버를 사용하여 제작하는데, 버 크기와 밀링 장 비의 절삭 동작 범위는 임시 보철물의 제작에 있어 제한 적인 요소이다. ${ }^{9}$ 따라서 제작 과정의 차이가 적층 가공 방 식이 절삭 가공 방식보다 교합 영역에서의 보철물의 적 합에 유의한 영향을 미친다는 것을 나타낸다.

보철물의 변연 및 내면 적합도는 $2 \mathrm{D}$ 또는 $3 \mathrm{D}$ 방법을 사용하여 측정할 수 있다. 보철물 적합도에 관한 $2 \mathrm{D}$ 측 
정 방법에는 절단면 측정법, 실리콘 복제 방법, 마이크로 $\mathrm{CT}$ 측정법 등이 있다. ${ }^{23,24} 2 \mathrm{D}$ 측정의 주요 단점으로 표본 크기가 제한되어 있어 내면을 측정할 수 있는 영역이 제 한되어 있으며 단일 위치에서만 내면 간격을 측정할 수 있다는 것이다. ${ }^{25} 3 \mathrm{D}$ 스캔 데이터 중첩법은 가상 공간의 변연 및 내면 영역의 여러 지점에서 두께를 측정할 수 있 고, 비 파괴적인 장점이 있어, ${ }^{26}$ 본 연구에서는 $3 \mathrm{D}$ 스캔 데이터 중첩법을 사용하였다.

본 연구에서는 $3 \mathrm{D}$ 프린터로 제작된 모형이 아닌 석고 모형으로 실험을 진행하였다. Anadioti 등 22 은 $3 \mathrm{D}$ 프린팅 기술 중 하나인 SLA 방식으로 제작된 모형으로 보철물 을 제작하였을 때 석고 모형으로 제작된 모형으로 제작 된 보철물보다 내면 적합도가 유의하게 높은 차이를 보 였다. Jang 등 ${ }^{28}$ 도 $3 \mathrm{D}$ 프린터로 제작된 모형을 사용하여 제작된 보철물이 석고 모형을 사용하여 제작된 보철물보 다 유의하게 높은 차이를 보였다. 따라서 본 연구에서는 석고 모형을 사용하여 실험을 진행하였다.

본 연구의 한계점은 다음과 같다. 본 연구는 실제 구 강 환경을 재현할 수 없었다. 따라서 본 연구를 뒷받침 하 기 위해서는 실제 구강 내에서의 임시 보철물의 적합도를 확인하는 추가 연구가 필요하다. 또한 시편의 수가 제한 적이고 간격 측정 기준점의 수가 적어 변연 및 내면을 부 분적인 영역에서만 보여주었다는 사실을 고려하여야 한 다. 따라서 임시 보철물에 대한 $3 \mathrm{D}$ 프린터 및 밀링 장비 의 적용을 넓히려면 임상 시험 및 장기적인 연구가 추가 로 수행되어야 한다.

\section{결론}

본 연구는 적층 가공 방식과 절삭 가공 방식을 이용하 여 임시 보철물을 제작하였으며, $3 \mathrm{D}$ 스캔 데이터 중첩법 을 사용하여 변연 및 내면의 간격을 측정하였을 때, 그에 따른 결론은 다음과 같다.

1. 3 종의 $3 \mathrm{D}$ 프린터와 1 종의 밀링 장비로 제작된 임시 보철물의 절대 변연 간격은 유의한 차이를 보이지 않았다.

2. 밀링 장비로 제작된 임시 보철물은 $3 \mathrm{D}$ 프린터보다 작은 축벽 간격과 높은 교합 간격을 보였다.

3. 3 종의 $3 \mathrm{D}$ 프린터로 제작된 임시 보철물의 변연 적 합도는 모두 임상적 허용 범위 $(<120 \mu \mathrm{m})$ 에 있었으 므로, 본 연구에서 사용된 $3 \mathrm{D}$ 프린터는 임시 보철물 제작을 위해서 충분히 사용될 수 있다.

\section{Acknowledgments}

본 연구는 산업통상자원부와 한국산업기술진흥원의 “국가혁신클러스터사업(P0006691, 레이저 활용 수요자 맞춤 멀티형 핸드피스 시스템 개발)"의 지원을 받아 수행 된 연구결과임, 또한 2020년도 산업통상자원부 및 산업 기술평가관리원(KEIT) 연구비 지원에 의한 연구임(과제 번호: 10062635).

\section{ORCID}

Young-Tak Son https://orcid.org/0000-0001-8893-5369

KeunBaDa Son http://orcid.org/0000-0002-3177-8005

Kyu-Bok Lee http://orcid.org/0000-0002-1838-7229

\section{References}

1. Burns DR, Beck DA, Nelson SK. A review of selected dental literature on contemporary provisional fixed prosthodontic treatment: report of the committee on research in fixed prosthodontics of the academy of fixed prosthodontics. J Prosthet Dent 2003;90:474-97.

2. Lee SH. Esthetic considerations for porcelain fused to metal restorations. J Korean Dent Assoc 1982; 20:127-30.

3. Lee WS, Lee DH, Lee KB. Evaluation of internal fit of interim crown fabricated with CAD/CAM milling and 3D printing system. J Adv Prosthodont 2017;9:265-70.

4. McLean JW, von Fraunhofer JA. The estimation of cement film thickness by an in vivo technique. $\mathrm{Br}$ Dent J 1971;131:107-11.

5. Syed M, Chopra R, Sachdev V. Allergic reactions to dental materials-a systematic review. J Clin Diagn Res 2015;9:ZE04-9.

6. Arora A, Yadav A, Upadhyaya V, Jain P, Verma M. Comparison of marginal and internal adaptation of copings fabricated from three different fabrication techniques: An in vitro study. J Indian Prosthodont Soc 2018;18:102-7.

7. Alharbi N, Osman R, Wismeijer D. Effects of build direction on the mechanical properties of 3Dprinted complete coverage interim dental restora- 
tions. J Prosthet Dent 2016;115:760-7.

8. Park ME, Shin SY. Three-dimensional comparative study on the accuracy and reproducibility of dental casts fabricated by $3 \mathrm{D}$ printers. J Prosthet Dent 2018;119:861.e1-861.e7.

9. Sun J, Zhang FQ. The application of rapid prototyping in prosthodontics. J Prosthodont 2012;21: 641-4.

10. Torabi K, Farjood E, Hamedani S. Rapid prototyping technologies and their applications in prosthodontics, a review of literature. J Dent (Shiraz) 2015;16:1-9.

11. Mai HN, Lee KB, Lee DH. Fit of interim crowns fabricated using photopolymer-jetting 3D printing. J Prosthet Dent 2017;118:208-15.

12. Stopp S, Wolff T, Irlinger F, Lueth T. A new method for printer calibration and contour accuracy manufacturing with 3D-print technology. Rapid Prototyping J 2008;14:167-72.

13. Ebert J, Ozkol E, Zeichner A, Uibel K, Weiss O, Koops U, Telle R, Fischer H. Direct inkjet printing of dental prostheses made of zirconia. J Dent Res 2009;88:673-6.

14. Kim SB, Kim NH, Kim JH, Moon HS. Evaluation of the fit of metal copings fabricated using stereolithography. J Prosthet Dent 2018;120:693-8.

15. Liu Y, Ye H, Wang Y, Zhao Y, Sun Y, Zhou Y. Threedimensional analysis of internal adaptations of crowns cast from resin patterns fabricated using computer-aided design/computer-assisted manufacturing technologies. Int J Prosthodont 2018;31:386-93.

16. Rayyan MM, Aboushelib M, Sayed NM, Ibrahim A, Jimbo R. Comparison of interim restorations fabricated by CAD/CAM with those fabricated manually. J Prosthet Dent 2015;114:414-9.

17. Alharbi N, Alharbi S, Cuijpers VMJI, Osman RB, Wismeijer D. Three-dimensional evaluation of marginal and internal fit of 3D-printed interim restorations fabricated on different finish line designs. J Prosthodont Res 2018;62:218-26.

18. Yu BY, Son KBD, Lee KB. Evaluation of intaglio surface trueness and margin quality of interim crowns in accordance with the build angle of stereolithography apparatus 3-dimensional printing. J Prosthet Dent 2020 Aug 14;S0022-3913(20)30385-1. doi:10.1016/
j.prosdent.2020.04.028.[Epub ahead of print]

19. Grajower R, Zuberi Y, Lewinstein I. Improving the fit of crowns with die spacers. J Prosthet Dent 1989;61:555-63.

20. Puebla K, Arcaute K, Quintana R, Wicker RB. Effects of environmental conditions, aging, and build orientations on the mechanical properties of ASTM type I specimens manufactured via stereolithography. Rapid Prototyping J 2012;18:374-88.

21. Zoellner A, Brägger U, Fellmann V, Gaengler P. Correlation between clinical scoring of secondary caries at crown margins and histologically assessed extent of the lesions. Int J Prosthodont 2000;13:453-9.

22. Anadioti E, Aquilino SA, Gratton DG, Holloway JA, Denry I, Thomas GW, Qian F. 3D and 2D marginal fit of pressed and CAD/CAM lithium disilicate crowns made from digital and conventional impressions. J Prosthodont 2014;23:610-7.

23. Lee $\mathrm{HH}$, Lee $\mathrm{DH}$, Lee KB. In vitro evaluation methods on adaptation of fixed dental prosthesis. J Dent Rehabil Appl Sci 2017;33:63-70.

24. Son KBD, Lee SB, Kang SH, Park JS, Lee KB, Jeon MS, Yun BJ. A comparison study of marginal and internal fit assessment methods for fixed dental prostheses. J Clin Med 2019;8:785.

25. Groten M, Axmann D, Pröbster L, Weber H. Determination of the minimum number of marginal gap measurements required for practical in-vitro testing. J Prosthet Dent 2000;83:40-9.

26. Kuhn K, Ostertag S, Ostertag M, Walter MH, Luthardt RG, Rudolph H. Comparison of an analog and digital quantitative and qualitative analysis for the fit of dental copings. Comput Biol Med 2015;57:32-41.

27. Revilla-Léon M, Olea-Vielba M, Esteso-Saiz A, Matínez-KIemm I, Özcan M. Marginal and internal gap of handmade, milled and 3D printed additive manufactured patterns for pressed lithium disilicate onlay restorations. Eur J Prosthodont Restor Dent 2018;26:31-8.

28. Jang Y, Sim JY, Park JK, Kim WC, Kim HY, Kim JH. Accuracy of 3-unit fixed dental prostheses fabricated on 3D-printed casts. J Prosthet Dent 2020;123:135-42. 


\section{$3 \mathrm{D}$ 프린팅 및 밀링 방법으로 제작된 임시 보철물 적합도 비교 분석}

손영탁 $^{1,2}$ 대학원생, 손큰바다 ${ }^{1,2}$ 대학원생, 이규복 ${ }^{1,2,3 *}$ 교수

${ }^{1}$ 경북대학교 대학원 치의과학과

${ }^{2}$ 경북대학교 첨단치과의료기기개발연구소

${ }^{3}$ 경북대학교 치과대학 치과보철학교실

목적: 본 연구의 목적은 서로 다른 제작 방법인 절삭 가공과 적층 가공 기술로 제작된 임시 보철물의 변연 및 내면 적합도 를 평가하는 것이다.

연구 재료 및 방법: 상악 우측 제1대구치를 도재 수복을 위한 지대치 모형으로 준비하였다. 석고를 이용하여 총 40 개의 실험 모형으로 복제하였고, 각각의 실험 모형을 구강 스캐너를 사용하여 스캔 데이터를 획득하였다. 3종의 3D 프린터 (Meg-printer 2; Megagen, Zenith U; Dentis 그리고 Zenith D; Dentis) 및 1종의 밀링 장비(imes-icore 450i; imes-icore $\mathrm{GmbH}$ 를 사용하여 각 그룹당 10 개의 임시 보철물을 제작하였다. 임시 보철물의 내면에 실리콘을 채우고 모형에 적합 하여 중합이 완료된 후, 실리콘으로 내면이 복제되어 있는 실험 모형을 구강 스캐너를 사용하여 스캔 데이터를 획득하였 다. 3차원 검사 소프트웨어(Geomagic control X; 3D Systems)를 이용하여 변연 간격, 절대 변연 간격, 샘퍼, 축벽, 교두, 교합 영역의 적합도를 분석하였다. 통계 분석은 제작 방법의 차이를 비교하기 위해서 Kruskal-Wallis test를 사용하여 검 증하였으며, 사후 검정을 위해서 Mann-Whitney U-test and Bonferroni correction method을 사용하였다 $(\alpha=0.05)$.

결과 : 3 종의 $3 \mathrm{D}$ 프린터와 1 종의 밀링 장비에서 제작된 임시 보철물의 절대 변연 간격은 유의한 차이를 보이지 않았다 $(P$ $=0.812)$. 축벽, 교합 간격에서 밀링 장비와 $3 \mathrm{D}$ 프린터 사이에 유의한 차이를 보였다 $(P<0.001)$.

결론: 3 종의 $3 \mathrm{D}$ 프린터로 제작된 임시 보철물의 변연 적합도는 모두 임상적 허용 범위 $(<120 \mu \mathrm{m})$ 에 있었으므로, 적합도 측면에서 본다면 임시 보철물 제작을 위해서 충분히 사용될 수 있다.

(구강회복응용과학지 2020;36 (4):254-61)

주요어: $3 \mathrm{D}$ 프린터; 밀링; 임시 보철물; 변연 적합; 중첩

*교신저자: 이규복

(41940)대구광역시 중구 달구벌대로 2177 경북대학교 치과대학 치과보철학교실, 첨단치과의료기기개발연구소

Tel: 053-600-7674 | Fax: 053-427-0778 | E-mail: kblee@knu.ac. kr

접수일: 2020년 10월 5일 | 수정일: 2020년 10월 29일 | 채택일: 2020년 10월 30일 